\title{
Preparation and Characterization of Biodegradable Composited Films Based on Potato Starch/Glycerol/Gelatin
}

\author{
Xiaoqing Niu $\mathbb{D}^{\mathbb{1}},^{1,2,3}$ Qianyun Ma $\mathbb{D}^{1,2,3}$ Shuiling Li $\mathbb{D}^{1},{ }^{1}$ Wenxiu Wang $\mathbb{D}^{1},{ }^{1}$ Yajuan $M a \mathbb{D}^{1}$ \\ Hongqian Zhao $\mathbb{D}^{1},{ }^{1}$ Jianfeng Sun $\mathbb{D}^{1,2,3}$ and Jie Wang ${ }^{1}$ \\ ${ }^{1}$ College of Food Science and Technology, Hebei Agricultural University, 289th Lingyusi Street, Lianchi District, Baoding, China \\ ${ }^{2}$ Hebei Agricultural Products Processing Technology Innovation Center, Baoding, Hebei, China \\ ${ }^{3}$ Sino-US and Sino-Japan Joint Center of Food Science and Technology, Baoding, Hebei, China
}

Correspondence should be addressed to Jianfeng Sun; causunjf@hebau.edu.cn

Received 13 November 2020; Revised 18 December 2020; Accepted 15 January 2021; Published 28 January 2021

Academic Editor: Hadi Hashemi Gahruie

Copyright (C) 2021 Xiaoqing Niu et al. This is an open access article distributed under the Creative Commons Attribution License, which permits unrestricted use, distribution, and reproduction in any medium, provided the original work is properly cited.

The use of plastics is resisted worldwide. Therefore, finding alternatives to plastic packaging products is an urgent issue. This work was dedicated to the preparation of biodegradable composited films with potato starch, glycerol, and gelatin. The formulation of the biodegradable film was first optimized via response surface methodology combined with the multi-index comprehensive evaluation method that considered physical properties (thickness, water solution (WS), tensile strength (TS) and elongation at break $(E \%))$ and barrier property (light transmittance $(T \%)$ ). Results indicated that the optimal conditions were $2.5 \%$ starch, $2.0 \%$ glycerol, and 1.5\% gelatin (based on water). The optimized film presented excellent properties with TS of $4.47 \mathrm{MPa}, E \%$ of $109.91 \%$, WS of $43.64 \%$, and $T \%$ of $41.21 \%$ at $500 \mathrm{~nm}$, and the comprehensive evaluation score of the composite film was 28.68. Moreover, a model verification experiment was further conducted, which proved that the predicted value highly matched experimental values, indicting the credibility and accuracy of the model. The resulting films were further characterized on the basis of rheological measurements, Fourier transform infrared spectroscopy (FTIR), and scanning electron microscopy (SEM). The rheological measurements proved that the film-forming solution exhibited low shear viscosity and non-Newtonian fluid behavior. FTIR and SEM revealed excellent compatibility among starch, glycerol, and gelatin. Hence, the resulting optimized film may be expected to provide theoretical basis and technical support for the food packing industry.

\section{Introduction}

In the food industry, food packaging is required to enhance food protection and guarantee shelf life on the basis of their appropriate physicochemical features $[1,2]$. Petroleum-based plastic packaging is still widely used due to its cost-effectiveness. However, with the worsening of environmental issues caused by nonrenewable and nondegradable plastic packaging and the serious harm to human health due to the accumulation of plastic waste $[3,4]$, some prohibitions about petroleum-based plastic packaging have been enforced. Internationally, the European Chemicals Agency has limited the use of conventional synthetic plastic polymers for food packaging [5]. In the domestic setting, plastic waste materials have been prohibited from importation due to their toxicity $[6,7]$. Therefore, to overcome these issues, replacing traditional plastic packaging with renewable, biodegradable materials has attracted considerable attention in recent decades. Generally, biodegradable packaging films were produced by natural biodegradable materials included polysaccharides, proteins, lipids, and their complexes, which make up for the drawbacks of plastic and solve those root environmental issues caused by plastic waste. Among these natural biodegradable films, starchbased films have incomparable advantages included abundant, low-cost, high film transparency, over other food packaging materials, which has been proved that starch-based film has exceed $60 \%$ of the total biodegradable film [8]. 
Starch is a highly annually renewable and high-molecular-weight polymer material that is composed of two types of $\alpha$-glucan, namely amylose and amylopectin $[9,10]$. Amylose is a linear polysaccharide that is connected by $\alpha$-1,4-glycosidic bonds, and that presents excellent filmforming property similar to fibers [11]. Moreover, the $\alpha-1,4-$ glycosidic bonds and $\alpha$-1,6-glycosidic bonds present in amylopectin are conducive to the thickening effect and freeze-thaw stability [12]. The proportion of amylose and amylopectin in various sources of starch is also different and directly affects film-forming properties [13, 14]. Therefore, increasing efforts have been devoted to the research of various resources of starch-based films $[9,15,16]$. The maize starch matrix film was produced and it was found that the films possessed low tensile strength (TS) and water vapor permeability (WVP), which could be enhanced by zein blended, and great compatibility with maize starch matrix [10]. Chollakup et al. [17] investigated cassava starch film, who proved the hydrophobic interactions and hydrogen bonding present in cassava starch and whey protein blended films to explain their barrier mechanisms at the molecular level. Lin et al. [18] utilized cellulose nanocrystals and PVA (polyvinyl alcohol)/glycerol to modify the formability of oxidized starch films with excellent WVP, surface free energy, and oxygen resistance. The characteristic properties of starch-PLA (polylactic acid) composite films [19] significantly improved with the use of cellulosic strengthening agents (cellulosic fibers and cellulose nanocrystals) and coffee husk extracts to enhance tensile properties, reduced barrier permeability, and endowed additional antioxidant capacity to food packaging systems. These results indicated that the research on starch-based film from various resources had been continued, and the contribution of physicochemical and mechanical properties by a single starch is limited and needed to blend with other components to acquire desirable performances for improving product texture and resistance to various physical changes.

Furthermore, as potato staple food strategy initiated, potatos have been the largest noncereal food crop worldwide [20], and potato planting area expanded 6.7 million hectares (2020) [21]. The yield of potato starch also increased up to 96 million tonnes (2016) [22], which has been a promising natural carbohydrate for food packing material. The size of potato starch granules is relatively large $(25-100 \mu \mathrm{m})$, and exists in typile B-type crystallinity [23]. Also, in the presence of plasticizers and under high temperature and shearing conditions, potato starch would acquire thermoplastic property which was suitable for preparing biodegradable film [24]. However, the performance of potato starch-based films still needs to be improved to extend the application in food package because of their poor water resistance. To address such issue, plasticizing agents and other active ingredients were incorporated to endow various advantages to films. Glycerol has been reported as the most starch-compatible plasticizing agent that can endow polymers with flexibility and resilience $[25,26]$. Moreover, gelatin, a protein of animal origin, exhibits excellent thermoreversible capability and thermal stability, presenting possible barrier performance $[27,28]$.
Although a range of various composite films has been investigated, few pieces of research were conducted about the optimized formulation of the composite film via response surface methodology (RSM) combined with the multi-index comprehensive evaluation method that considered physical properties (thickness, water solution (WS), tensile strength (TS), and elongation at break $(E \%)$ ) and barrier property (light transmittance (T\%)). Thus, this study aimed to prepare a durable biodegradable film with excellent comprehensive performance based on potato starch, glycerol, and gelatin. The optimized films were further characterized by scanning electron microscopy (SEM), rheological measurements, and Fourier transform infrared spectroscopy (FTIR).

\section{Materials and Methods}

2.1. Materials. Potato starch was purchased from a local market in Baoding, China. Glycerol was purchased from Tianjin Kemiou Chemical Reagent Co., Ltd (Tianjin, China). Edible gelatin, extracted from pig skin, was obtained from Sinopharm Chemical Reagent Co., Ltd (Shanghai, China).

2.2. Preparation of Complex Films. Potato starch was dispersed in $100 \mathrm{~mL}$ of distilled water and stirred for $30 \mathrm{~min}$ at $80^{\circ} \mathrm{C}$ until completely gelatinized. Glycerol and gelatin were successively added to the film-forming solution. The mixtures were degassed for another $30 \mathrm{~min}$ by using an ultrasonic device (SK5200H, Ningbo Scientz Biotechnology Co., Ltd. Zhejiang, China), then casting onto a plate, and dried at $40^{\circ} \mathrm{C}$ for $36 \mathrm{~h}$ in an incubator [29]. After this period, the films were peeled for further analysis.

2.3. Comprehensive Score Calculation. Membership degree and principal component analysis (PCA) were used to evaluate the films comprehensively. In accordance with importance, the indexes of the films were normalized to optimize the production process. Each index weight was determined. Indexes with high membership, such as TS and elongation at break $(E \%)$, were calculated using equation (1). WS (water solution) and light transmittance (T\%) were calculated with equation (2):

$$
\begin{aligned}
& P=\frac{A_{i}-A_{\text {min }}}{A_{\text {max }}-A_{\text {min }}}, \\
& P=\frac{A_{\max }-A_{i}}{A_{\max }-A_{\min }},
\end{aligned}
$$

where $P$ is the index membership degree; $A_{i}$ is the actual value; $A_{\min }$ is the minimum of the same index; $A_{\max }$ is the maximum of the same index.

The comprehensive score $(Y)$ was calculated with the following equation:

$$
\begin{aligned}
Y= & a_{1} \times P_{1}+a_{2} \times P_{2}+a_{3} \times P_{3} \\
& +a_{4} \times P_{4}+a_{5} \times P_{5},
\end{aligned}
$$


where $a_{1}, a_{2}, a_{3}, a_{4}$, and $a_{5}$ are the weights of thickness, TS, $E$ $\%$, WS, and T\%, respectively, and $P_{1}, P_{2}, P_{3}, P_{4}, P_{5}$ are membership degrees of thickness, TS, E\%, WS, and T\%, respectively.

2.4. Design of Experiments. Film concentration ratios were optimized by using RSM to investigate the synergistic effect of the variables. Three-level (starch concentration $X_{1}[1-6 \mathrm{~g} /$ $100 \mathrm{~mL}]$, glycerol concentration $X_{2}[0.5-3 \mathrm{~g} / 100 \mathrm{~mL}]$, and gelatin concentration $X_{3}[0.5-3 \mathrm{~g} / 100 \mathrm{~mL}]$ ) factorial design was applied to investigate the effects of the parameters on WVP, TS, T\%, and E\%. After preliminary tests, the appropriate levels of the independent variables needed to obtain the optimal characteristic properties of the biodegradable composite film were measured.

A total of 17 formulas with five replicates at the center point were evaluated to ensure the repeatability of the RSM model. These formulas are listed in Table 1 , which clearly records the coded and uncoded levels of starch, glycerol, and gelatin concentrations. The response for each formulation was independently evaluated with three replicates. A random experimental design was used to eliminate the effects of possible uncontrolled factors.

2.5. Verification Test. Verification procedures were applied to determine the optimal level of composite films with excellent properties. The experimental data and fitted value predicted by the model were compared to verify the validity and adequacy of the RSM model.

2.6. Acquisition of Light Transmission Curves. UV-vis spectrophotometer $(\alpha-1500$, Shanghai, China) was used to acquire the light transmittance spectra of the complex films. Briefly, the film was cut into strips $(1 \times 4 \mathrm{~cm})$ and placed closely to the inner surface of the cuvette to record the $T \%$ with three replicates ranging from $400 \mathrm{~nm}$ to $800 \mathrm{~nm}$.

2.7. Rheology of Film-Forming Solutions. The static rheological properties of the film-forming solutions were determined by using a rotational rheometer (RheolabQC, Anton Paar Instruments Ltd., Japan) equipped with a concentric cylinder (CC 39, $40 \mathrm{~mm}$ diameter, Austria) and temperature control system (TEZ 150P-C). The shear rate was varied from $1 \mathrm{~s}^{-1}$ to $300 \mathrm{~s}^{-1}$ with the Ramp log procedure at $25^{\circ} \mathrm{C}$ and the flow behavior was recorded every $30 \mathrm{~s}$.

The rheological properties of films were further stimulated by the Cross model [30]:

$$
\eta=\eta_{\infty}+\frac{\eta_{0}-\eta_{\infty}}{1+(K \gamma)^{\mathrm{P}}}
$$

where $\eta, \eta_{0}$, and $\eta_{\infty}$ represented viscosity, the initial shear viscosity, and infinite shear viscosity, respectively. $\gamma$ indicated shear rate $\left(\mathrm{s}^{-1}\right)$, and $K$ and $\mathrm{P}$ were time constant and dimensionless exponent, respectively.
2.8. Physical Properties. The thicknesses of the films was recorded by using an electronic thickness gauge (EC770, Shanghai, China) at 10 random positions. An autotensile tester (PARAM XLW-PC, Jinan, China) was used to measure the TS and elongation at break $(E \%)$ of the films at a cross-head speed of $300 \mathrm{~mm} / \mathrm{s}$ [31]. T\% was measured with a UV-vis spectrophotometer at $500 \mathrm{~nm}$.

WVP of the film was measured by the gravimetric method [32]. The film $(8 \mathrm{~cm} \times 8 \mathrm{~cm})$ was sealed in a circular cup with $20 \mathrm{~g}$ anhydrous $\mathrm{CaCl}_{2}(0 \% \mathrm{RH}$ (relative humidity)). The cups were placed inside of desiccator with distilled water $(100 \% \mathrm{RH})$. The difference in RH promoted the transport of water vapor, which caused weight changes.

WS was tested according to the modified weight loss method [33] which was performed with three replicates to determine the WS of films. Briefly, at room temperature, a film $(2 \mathrm{~cm} \times 2 \mathrm{~cm})$ was weighed prior to dissolution in distilled water for $24 \mathrm{~h}$ and then removed and dried at $90^{\circ} \mathrm{C}$ to a constant weight. WS was calculated by the following equation:

$$
\mathrm{WS}=\frac{M_{1}-M_{2}}{M_{1}} \times 100 \%,
$$

where $M_{1}$ and $M_{2}$ are the initial and terminal weights of the films (dry basis), respectively.

2.9. Morphology of Films. The microstructures of crosssections and surfaces were measured by using a scanning electron microscope (JSM-7900F, Japan) with an accelerating voltage of $12.5 \mathrm{kV}$. Before the observation, the films were coated with a thin layer of gold.

2.10. FTIR Spectroscopy. FTIR spectra were acquired over the range of $500-4000 \mathrm{~cm}^{-1}$ in attenuated total reflection mode with a resolution of $4 \mathrm{~cm}^{-1}$ by using an FTIR spectrometer (Shimadzu Instrument Co. Ltd., Japan).

\section{Results and Discussion}

3.1. Light Transmission Analysis. The light transmittance of the film is an important index to directly affect consumer acceptance. And the light transmission curve of a resulting optimized film (starch + glycerol + gelatin) is shown in Figure 1(a). The remarkable UV barrier capability shown by the film over the UV range of $200-280 \mathrm{~nm}$ would protect food from oxidative deterioration [32]. This characteristic was due to the intermolecular hydrogen bond between starch and glycerol during the film-forming process, resulting in good miscibility [34]. The optical property of film is significantly reinforced with wavelength increasing. Moreover, over the visible range (at $500 \mathrm{~nm}$ ), the $T \%$ of films reached the maximum value then remained constant at approximately $90 \%$, indicating excellent transparency. Such high transmittance indicated the uniform of film. Perfectly clear food packaging would not adversely affect the consumer experience. The picture covered by these films could be clearly observed (Figure 1(b)), and further proved good transmittance. 
TABLE 1: Experiments design with coded and uncoded independent variables.

\begin{tabular}{|c|c|c|c|c|c|c|}
\hline \multirow{2}{*}{ Run } & \multicolumn{3}{|c|}{ Code variables } & \multicolumn{3}{|c|}{ Uncoded variables } \\
\hline & $X_{1}$ & $X_{2}$ & $X_{3}$ & Starch concentration & Glycerol concentration & Gelatin concentration \\
\hline 1 & 1.000 & 0.000 & 1.000 & 4 & 2 & 2 \\
\hline 2 & 0.000 & 1.000 & -1.000 & 3 & 2.5 & 1 \\
\hline 3 & 0.000 & 0.000 & 0.000 & 3 & 2 & 1.5 \\
\hline 4 & 0.000 & 1.000 & 1.000 & 3 & 2.5 & 2 \\
\hline 5 & -1.000 & 0.000 & 1.000 & 2 & 2 & 2 \\
\hline 6 & 0.000 & 0.000 & 0.000 & 3 & 2 & 1.5 \\
\hline 7 & -1.000 & 0.000 & -1.000 & 2 & 2 & 1 \\
\hline 8 & -1.000 & 1.000 & 0.000 & 2 & 2.5 & 1.5 \\
\hline 9 & -1.000 & -1.000 & 0.000 & 2 & 1.5 & 1.5 \\
\hline 10 & 0.000 & 0.000 & 0.000 & 3 & 2 & 1.5 \\
\hline 11 & 0.000 & 0.000 & 0.000 & 3 & 2 & 1.5 \\
\hline 12 & 1.000 & 0.000 & -1.000 & 4 & 2 & 1 \\
\hline 13 & 0.000 & -1.000 & -1.000 & 3 & 1.5 & 1 \\
\hline 14 & 1.000 & -1.000 & 0.000 & 4 & 1.5 & 1.5 \\
\hline 15 & 0.000 & 0.000 & 0.000 & 3 & 2 & 1.5 \\
\hline 16 & 0.000 & -1.000 & 1.000 & 3 & 1.5 & 2 \\
\hline 17 & 1.000 & 1.000 & 0.000 & 4 & 2.5 & 1.5 \\
\hline
\end{tabular}

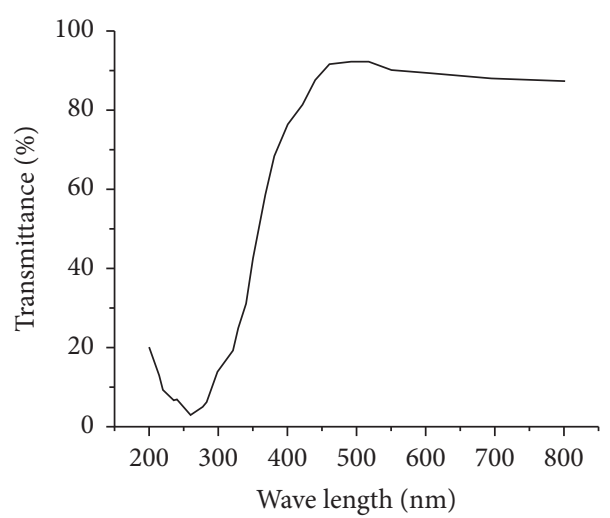

(a)

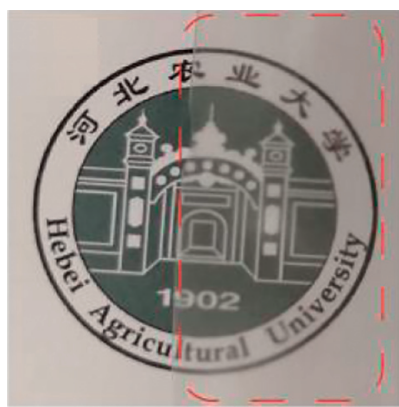

Starch + glycerol

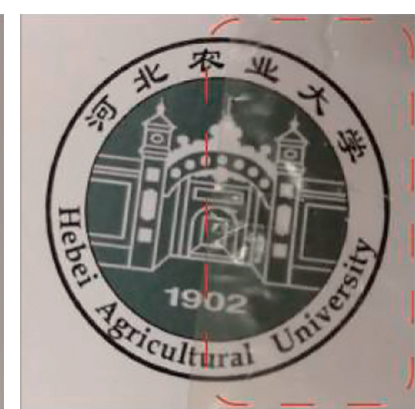

Starch + gelatin

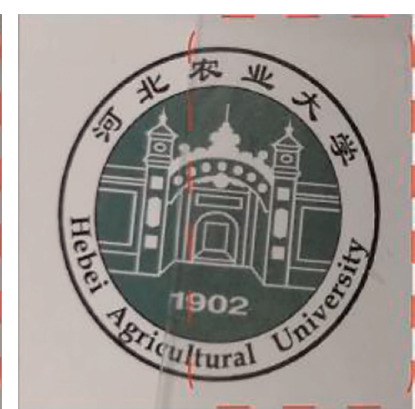

Starch + glycerol + gelatin

(b)

Figure 1: (a) The light transmission curve. (b) The pictures of the films.

3.2. Comprehensive Evaluation of the Composite Film. PCA was performed by using SPSS19.0 software on six randomly selected sets of data (Table 2) to evaluate film comprehensive performance. According to the criterion of eigenvalues exceeding 1, the results of PCA (Table 3) showed that the three principal components (PC1, PC2, and PC3) are extracted and the variance contributions of $\mathrm{PC} 1, \mathrm{PC} 2$, and PC3 were $40.425 \%, 29.065 \%$, and $20.892 \%$, respectively. In addition, the cumulative variance of the three components reached $90.382 \%$, indicating that PC1, PC2, and PC3 could contain most of the information (more than 90\%) of all indexes (TS, E\%, WS, thickness, and T\%) and reflect the comprehensive performance of the films. Therefore, PC1, PC2, and PC3 could replace the original complex indexes. 
TABLE 2: Test data randomly selected for principal component analysis.

\begin{tabular}{lcccrr}
\hline Indexes & Thickness $(\mathrm{mm})$ & $E \%$ & TS (MPa) & T\% & WS \% \\
\hline 1 & 0.071 & 40 & 3.350 & 0.284 & 0.2674 \\
2 & 0.060 & 198.95 & 1.130 & 0.414 & 0.298 \\
3 & 0.066 & 102.15 & 1.640 & 0.439 & 0.3256 \\
4 & 0.073 & 166.17 & 1.987 & 0.123 & 0.4331 \\
5 & 0.070 & 198.95 & 2.967 & 0.361 & 0.3197 \\
6 & 0.066 & & & & 0.367 \\
\hline
\end{tabular}

TABLE 3: Eigenvalues and variance contribution rates of related components.

\begin{tabular}{lccc}
\hline Principal components & Eigenvalue & Variance contribution rate (\%) & Cumulative variance contribution rate (\%) \\
\hline PC1 & 2.021 & 40.425 & 40.425 \\
PC2 & 1.453 & 29.065 & 69.489 \\
PC3 & 1.045 & 20.892 & 90.382 \\
PC4 & 0.388 & 7.766 & 98.148 \\
PC5 & 0.093 & 1.852 & 100.000 \\
\hline
\end{tabular}

Table 4 lists the factor loading matrix and the contribution rate of thickness, TS, E\%, and WS to PC1, PC2, and PC3 (eigenvalue $>1$ ). As shown in Table 4, thickness, E\%, and WS mainly affected PC1; TS mainly affected PC2; T\% and TS mainly affected PC3. After normalization, the percentages of thickness, TS, E\%, WS, and T\%, were $13 \%, 34 \%$, $18 \%, 30 \%$, and $5 \%$, respectively. The comprehensive score $(Y)$ was calculated by using the following equation in accordance with equations (1)-(3):

$$
\begin{aligned}
Y= & 13 \% \times P_{1}+34 \% \times P_{2}+18 \% \times P_{3} \\
& +30 \% \times P_{4}+5 \% \times P_{5} .
\end{aligned}
$$

3.3. RSM Analysis. RSM was applied to investigate the linear, quadratic, and interaction effects of each independent variable (starch, glycerol, and gelatin concentrations) on response values. All the response experimental data are listed in Table 5.

The different evaluation indexes, including the $\mathrm{F}$ value, the lack-of-fit value, and the correlation coefficient $R^{2}$, are presented in Table 6 to verify the model's adequacy and accuracy. The predictive model was extremely significant $(p<0.01)$. A low $p$ value indicates the high significance and applicability of the regression model. Moreover, the $p$ values of the linear $\left(X_{1}\right)$, quadratic $\left(X_{13}\right)$, and interactive $\left(X_{12}, X_{13}\right.$, and $\left.X_{23}\right)$ models were all less than 0.05 , which indicated that the model fits well with the measured data. $R^{2}$ and adj- $\mathrm{R}^{2}$ were used to prove the adequacy and goodness of fit of the applied model. A high $R^{2}$ value $\left(R^{2}>0.9\right)$ indicated the high reliability of the models and acceptable error between the calculated and experimental results. The insignificance between $R^{2}$ and $R^{2}$-adj indicated the adequate accuracy and applicability of the selected polynomial model. The response comprehensive score $(Y)$ was fitted with the regression equation as shown in the following equation:

$$
\begin{aligned}
Y & =50.96-7.92 X_{1}+4.12 X_{2}+2.71 X_{3}+0.012 X_{1} X_{2} \\
& -5.48 X_{1} X_{3}+0.95 X_{2} X_{3}-8.20 X_{12}-10.53 X_{22}-8.70 X_{32} .
\end{aligned}
$$

$3 \mathrm{D}$ response surfaces were used (Figure 2) to further interpret the effects of interactions among independent variables (starch, glycerol, and gelatin concentrations) on response value. The closer the bottom curve, which is the projection of the $3 \mathrm{D}$ response surface, to the ellipse, the more obvious the interaction effect and vice versa. In accordance with Table 5, the figure shows significant interaction between $X_{1}$ and $X_{2}$ and no significant interaction between $X_{1}$ and $X_{2}$ and between $X_{2}$ and $X_{3}$. Such results further indicated that the RSM model was reliable and veritable.

3.4. Verification Experiments. Verification experiments on the optimal variable concentrations $(2.40 \%$ starch, $2.11 \%$ glycerol, and $1.68 \%$ gelatin) and experimental concentrations $(2.5 \%$ starch, $2.0 \%$ glycerol, and $1.5 \%$ glycerin) were performed to validate the reliability and validity of the model equations. The results of the verification experiments are shown in Table 7. The acceptable percentage error between the predicted value and experimental value further demonstrated the reasonable adequacy of the response surface equations for responses and the reliability of the experiments.

Figure 3(a) depicts the variation curve of viscosity with the shear rate of 3 film solutions. Film thickness and uniformity are affected by the fluidity (viscosity) of filmforming solutions. The figure shows that the viscosity of the film-forming solutions decreased with the increase in shear rate, exhibiting non-Newtonian fluid behavior that might be attributed to the rearrangement of entangled molecules under high-speed shear $[35,36]$. Such a result was in accordance with the finding of Glusac et al. [37], who proved that potato starch and zein proteins exhibited shear-thinning behavior. And the rheological behavior of the three films was successfully fitted by the Cross model (Table 8 ). The $p$ value of all films was lower than 1, which further proved the pseudoplastic fluids. $K$-value was related to the destruction of the molecular structure inside the fluid [30]. And the three-component film showed the smallest $K$-value, which indicated the least time needed to form a new network structure and hydrogen bonding [38]. 
TABLE 4: The factor loading matrix of three components.

\begin{tabular}{lcccc}
\hline Index & \multicolumn{3}{c}{ Principal components } & Percentage (\%) \\
& 1 & 2 & 0.575 & 13 \\
T\% & 0.514 & -0.538 & 0.062 & 34 \\
Thickness(mm) & 0.844 & 0.475 & -0.520 & 18 \\
E\% & 0.772 & 0.313 & 0.662 & 30 \\
TS (MPa) & 0.038 & 0.705 & 0.041 & 5 \\
WS (\%) & 0.668 & -0.586 & & \\
\hline
\end{tabular}

- indicated negative correlative.

TABLE 5: Experiments data of the responses.

\begin{tabular}{|c|c|c|c|c|c|c|}
\hline \multirow{2}{*}{ Runs } & \multicolumn{6}{|c|}{ Response } \\
\hline & Thickness (mm) & $E \%$ & $\mathrm{TS}(\mathrm{MPa})$ & $T \%(500 \mathrm{~nm})$ & Water solubility\% & Comprehensive scores $(Y)$ \\
\hline 1 & 0.076 & 87.633 & 9.873 & 36.4 & 52.6 & 25.90 \\
\hline 2 & 0.057 & 121.033 & 4.630 & 44.9 & 60.7 & 33.04 \\
\hline 3 & 0.071 & 138.300 & 2.217 & 38.0 & 51.3 & 36.77 \\
\hline 4 & 0.073 & 109.800 & 9.223 & 31.1 & 52.2 & 31.46 \\
\hline 5 & 0.079 & 101.733 & 10.800 & 33.1 & 58.5 & 29.85 \\
\hline 6 & 0.096 & 115.433 & 5.517 & 35.5 & 58.1 & 31.73 \\
\hline 7 & 0.084 & 66.900 & 9.573 & 36.1 & 46.7 & 20.41 \\
\hline 8 & 0.097 & 88.133 & 11.207 & 31.8 & 31.8 & 26.39 \\
\hline 9 & 0.056 & 157.400 & 2.327 & 52.8 & 35.8 & 41.77 \\
\hline 10 & 0.096 & 169.600 & 6.800 & 34.9 & 55.8 & 46.30 \\
\hline 11 & 0.079 & 195.300 & 18.230 & 38.7 & 60.2 & 56.35 \\
\hline 12 & 0.095 & 184.300 & 7.917 & 32.3 & 52.1 & 50.44 \\
\hline 13 & 0.082 & 60.867 & 22.400 & 32.2 & 42.3 & 22.68 \\
\hline 14 & 0.101 & 201.700 & 6.045 & 37.3 & 65.1 & 54.44 \\
\hline 15 & 0.084 & 173.200 & 6.907 & 35.5 & 53.6 & 47.26 \\
\hline 16 & 0.096 & 144.250 & 5.985 & 50.5 & 46.1 & 39.47 \\
\hline 17 & 0.056 & 197.733 & 3.750 & 48.9 & 48.7 & 52.70 \\
\hline
\end{tabular}

Each value represents the mean value of three determinations.

TABLE 6: ANOVA study for the model fitting.

\begin{tabular}{|c|c|c|c|c|c|}
\hline Source & SS & Df & $F$ value & $p$ value & Significant \\
\hline Model & 2010.48 & 9 & 11.31 & 0.0021 & $* *$ \\
\hline$X_{1}$ & 501.49 & 1 & 25.39 & 0.0015 & $* *$ \\
\hline$X_{2}$ & 135.80 & 1 & 6.88 & 0.0343 & $*$ \\
\hline$X_{3}$ & 58.54 & 1 & 2.97 & 0.1288 & \\
\hline$X_{1} X_{2}$ & 0.000625 & 1 & $3.16 E-05$ & 0.9957 & \\
\hline$X_{1} X_{3}$ & 120.01 & 1 & 6.08 & 0.0431 & * \\
\hline$X_{2} X_{3}$ & 3.59 & 1 & 0.188 & 0.6826 & \\
\hline$X_{12}$ & 282.79 & 1 & 14.32 & 0.0069 & $* *$ \\
\hline$X_{22}$ & 466.45 & 1 & 23.62 & 0.0018 & $* *$ \\
\hline$X_{32}$ & 318.35 & 1 & 16.12 & 0.0051 & $* *$ \\
\hline Residual & 138.25 & 7 & & & \\
\hline Lack-of-fit & 61.41 & 3 & 1.07 & 0.4571 & \\
\hline Pure error & 76.84 & 4 & & & \\
\hline \multirow[t]{2}{*}{ Cor. total } & 2148.73 & 16 & & & \\
\hline & & $R^{2}=0.9357$ & $R_{\text {Adj }}^{2}=0.8529$ & & \\
\hline
\end{tabular}

${ }^{*}$ represented significant $(p<0.05),{ }^{* *}$ represented extremely significant $(p<0.01)$.

The different viscosities of the film-forming solutions indicated different entanglement networks [30]. In principle, film-forming solutions become viscous with the increase in solute concentration. However, Figure 3(a) indicates that the film solution of the three mixed matrixes (starch + glycerol + gelatin) showed low viscosity. This result was consistent with Hussain et al. [39], who believed that the viscosity decrease could be attributed to the alteration in the macromolecular organization of the blended gelatin at a high shear rate. 


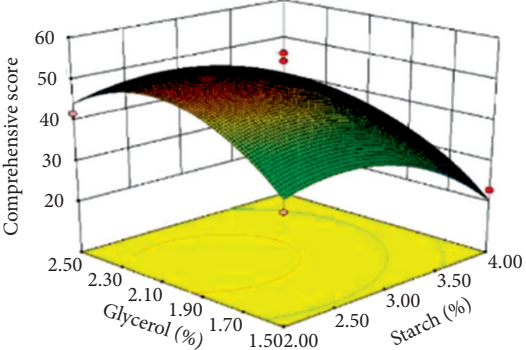

(a)

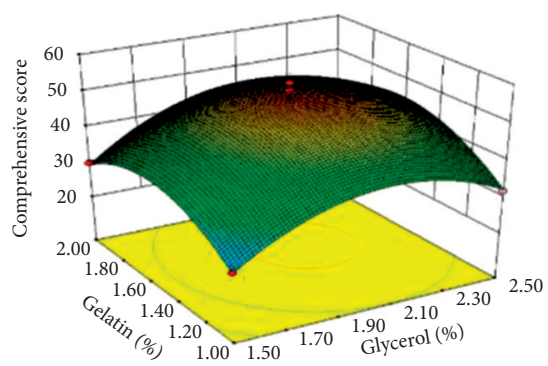

(b)

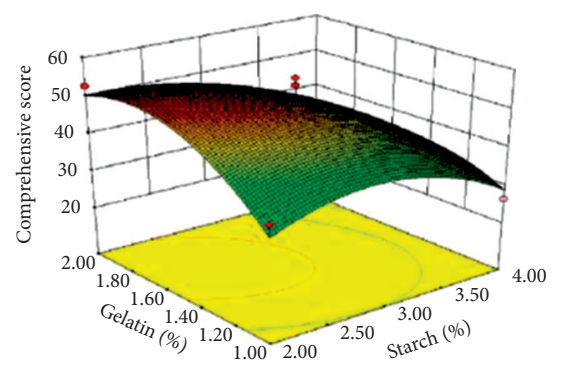

(c)

Figure 2: 3D responses surfaces.

TABle 7: Predicted and experimental data for the responses at the optimum point.

\begin{tabular}{lccc}
\hline Indexes & Predicted value & Experimental value & Percentage error $(\%)$ \\
\hline T\% & 44.37 & $41.21 \pm 0.13$ & 7.12 \\
Thickness $(\mathrm{mm})$ & 0.073 & $0.071 \pm 0.02$ & 2.73 \\
E\% & 102.15 & $109.91 \pm 2.31$ & 7.59 \\
TS $(\mathrm{MPa})$ & 4.52 & $4.47 \pm 1.21$ & 1.11 \\
WS $\%$ & 39.13 & $43.64 \pm 0.03$ & 11.53 \\
Comprehensive score & 27.48 & $28.68 \pm 0.79$ & 4.35 \\
\hline
\end{tabular}

Rheology of film-forming solutions.

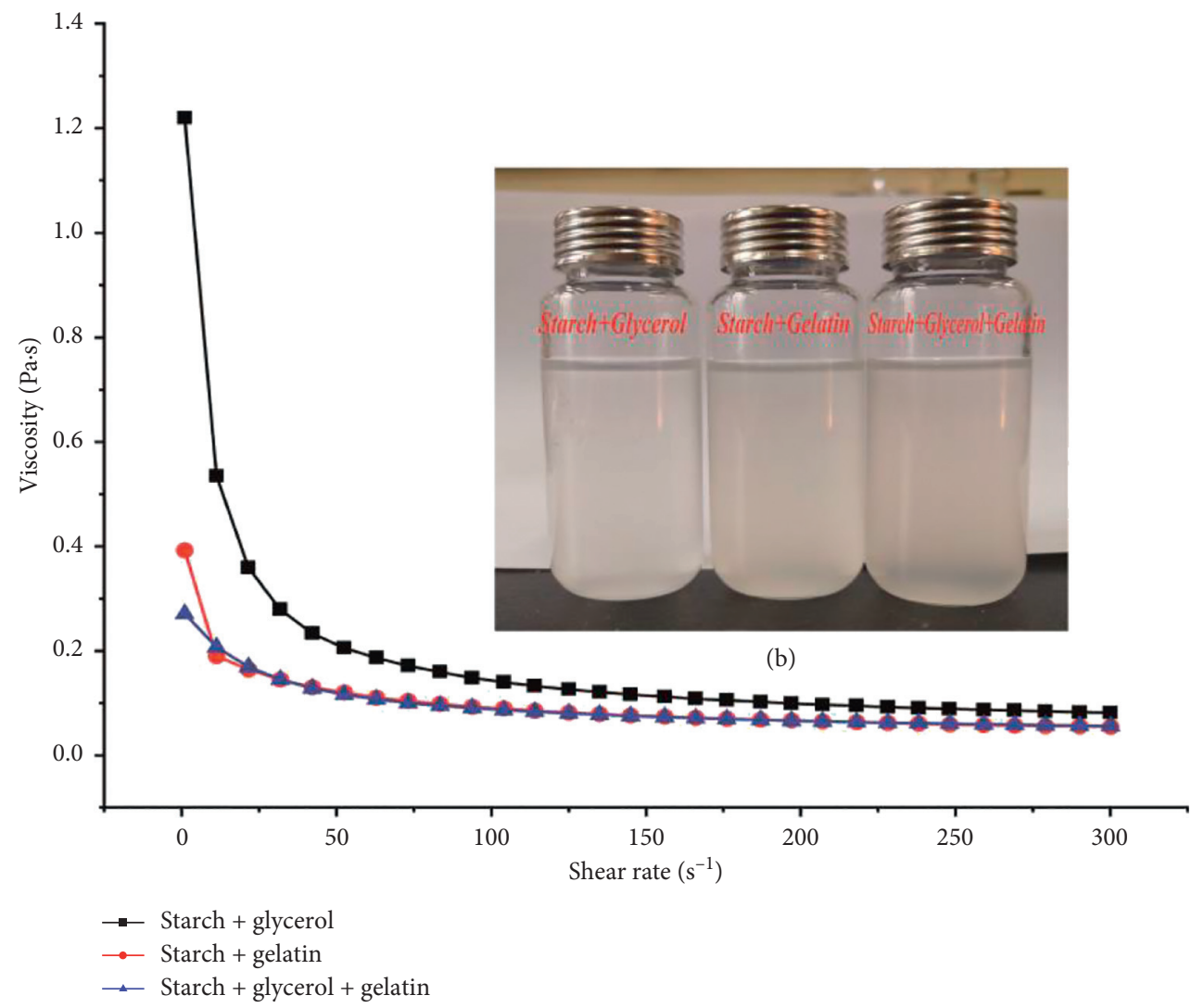

(a)

Figure 3: (a) Shear viscosity curves. (b) Pictures of film-forming solutions.

3.5. The Physical Properties of Films. The physical properties including thickness, TS, $E \%, T \%$, WS, and WVP of the three films were listed in Table 9. The optimized film (starch + glycerol + gelatin) showed high thickness due to the blend of three components. Meanwhile, lower WVP of the optimized three-component film was possibly attributed to 
TABLE 8: The correlation coefficient fitted by the Cross model.

\begin{tabular}{|c|c|c|c|c|}
\hline Sample & $\eta_{0}(\mathrm{~Pa} \cdot \mathrm{s})$ & $\mathrm{K}(\mathrm{s})$ & $p$ & $R^{2}$ \\
\hline Starch + glycerol + gelatin & $0.28202 \pm 0.00117$ & $0.03936 \pm 4.68937 E-4$ & $0.98729 \pm 0.0147$ & 0.99975 \\
\hline Starch + glycerol & $1.46702 \pm 0.01155$ & $0.18258 \pm 0.00453$ & $0.91593 \pm 0.01207$ & 0.99991 \\
\hline Starch + gelatin & $0.68782 \pm 0.11894$ & $0.55409 \pm 0.38086$ & $0.47097 \pm 0.06955$ & 0.99778 \\
\hline
\end{tabular}

TABLe 9: The physical performance of the optimized film.

\begin{tabular}{|c|c|c|c|c|c|c|}
\hline Sample & Thickness (mm) & TS (MPa) & $E \%$ & $T \%$ & WS (\%) & WVP $\left(\times 10^{-10} \mathrm{gs}^{-1} \mathrm{~m}^{-1} \mathrm{~Pa}^{-1}\right)$ \\
\hline Starch + glycerol + gelatin & $0.071 \pm 0.02^{\mathrm{a}}$ & $4.47 \pm 1.21^{\mathrm{b}}$ & $109.91 \pm 2.31^{\mathrm{b}}$ & $41.21 \pm 0.13^{\mathrm{a}}$ & $43.64 \pm 0.03^{\mathrm{a}}$ & $1.50 \pm 0.02^{\mathrm{c}}$ \\
\hline Starch + glycerol & $0.064 \pm 0.01^{b}$ & $4.83 \pm 0.5^{\mathrm{a}}$ & $138.32 \pm 11.94^{\mathrm{a}}$ & $41.12 \pm 0.34^{\mathrm{a}}$ & $44.83 \pm 0.31^{\mathrm{c}}$ & $1.56 \pm 0.04^{\mathrm{b}}$ \\
\hline Starch + gelatin & $0.068 \pm 0.03^{b}$ & $4.15 \pm 0.07^{\mathrm{c}}$ & $89.62 \pm 3.64^{c}$ & $41.09 \pm 0.18^{\mathrm{a}}$ & $43.77 \pm 0.53^{b}$ & $1.67 \pm 0.02^{\mathrm{a}}$ \\
\hline
\end{tabular}

Different letters indicated significant $(p<0.05)$.

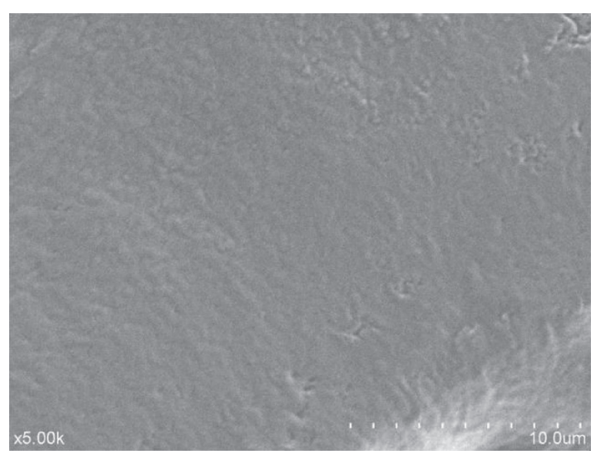

(a)

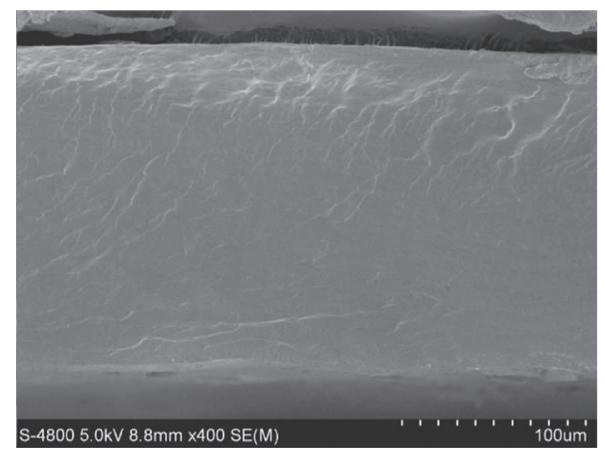

(b)

FIgURE 4: The micrographs of optimized complex film (a) Surface. (b) Cross section.

the forming of intermolecular hydrogen bonds between glycerol and starch with the matrix, resulting in strong interfacial adhesion [16] and lower WS indicated water resistance enhanced. Meanwhile, the lower TS and $E \%$ of the three-component film may probably be due to the agglomerates formed by the incorporation of gelatin, which disrupted the compactness of the hydrogen bonds [40]. Moreover, the $T \%$ showed no significance, which may be explained by the great miscibility of three components.

3.6. SEM Analysis. As shown in Figure 4, SEM was applied to observe the microstructures of the surface and cross section of the optimized film. The smoothness and homogeneity of the surfaces presented in Figure 4(a) indicated that the components dispersed well within each other. The appearance of surface wrinkles did not mean that the film was uneven and discontinuous. Such wrinkles might be caused by adhesion between the film and the plastic plate when the film was peeled off. Additionally, as shown in Figure 4(b), distinctive ridged structures were presented in the crosssections of the composite biodegradable film. The high uniformity of the biodegradable film was attributed to the plasticizing capability of glycerol and the thickening capability of gelatin. Furthermore, the numerous intermolecular hydrogen bonds that formed between hydroxyl groups in glycerol with the hydroxyl groups present in starch promoted close bonding in polymers [41] and further enhanced miscibility among starch, gelatin, and glycerol.

3.7. FTIR Analysis. The spectra of the single starch film and optimized biocomposite films are shown in Figure 5. Typically, the broadening of the $\mathrm{O}-\mathrm{H}$ and the decreasing of wavenumber could be possible due to the characteristic of hydrogen bonding interaction in the film [42]. For the control film (single starch film), the characteristic band around $3267 \mathrm{~cm}^{-1}$ was originally from the $\mathrm{O}-\mathrm{H}$ stretching vibration, and the band absorption intensity was broadened with incorporation with gelatin and glycerol. Also, the characteristic peak at $1644 \mathrm{~cm}^{-1}$ slightly shifts to $1636 \mathrm{~cm}^{-1}$. This phenomenon indicated the formation of hydrogen bonds.

The similar characteristic peaks at approximately 2940 and $2875 \mathrm{~cm}^{-1}$ in the three biocomposite film spectra were attributed to $\mathrm{C}-\mathrm{H}$ vibration and $\mathrm{C}=\mathrm{C}$ vibration, respectively [43]. The peaks at 1636 and $1023 \mathrm{~cm}^{-1}$ represented the $\mathrm{C}=\mathrm{O}$ and $\mathrm{C}-\mathrm{O}$ stretching vibrations of glycoside bonds in the starch branch. The intensity of the peak at $1023 \mathrm{~cm}^{-1}$ increased with the incorporation of glycerol, and the enhancement in the $-\mathrm{OH}$ stretching vibration at approximately $3267 \mathrm{~cm}^{-1}$ suggested the occurrence of association [44]. Cross-linking between polymers tightened in the presence of intermolecular hydrogen and hydrogenoxygen bonds (Figure 6). Such results illustrated the good 


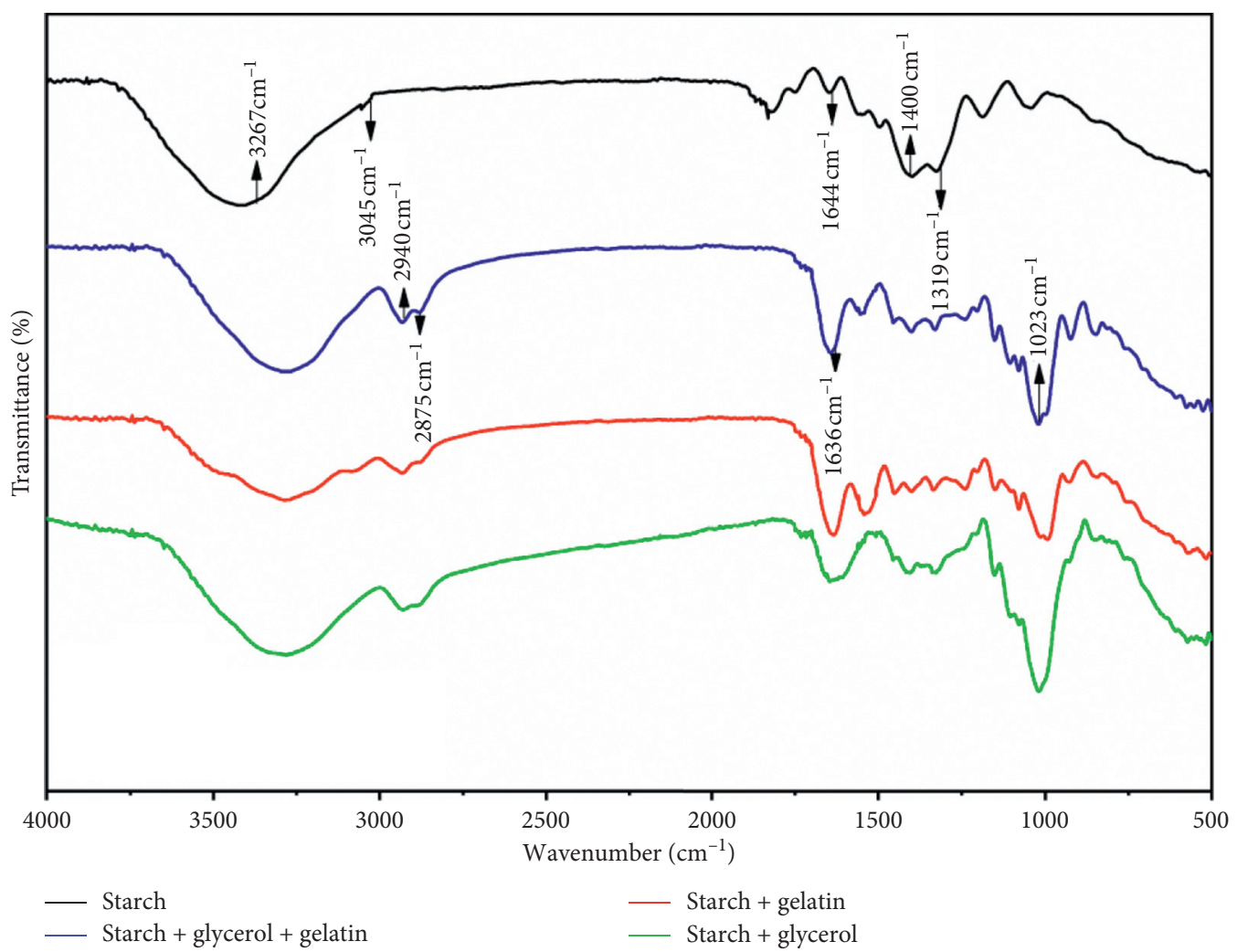

FIGURE 5: FTIR spectra of optimized films.
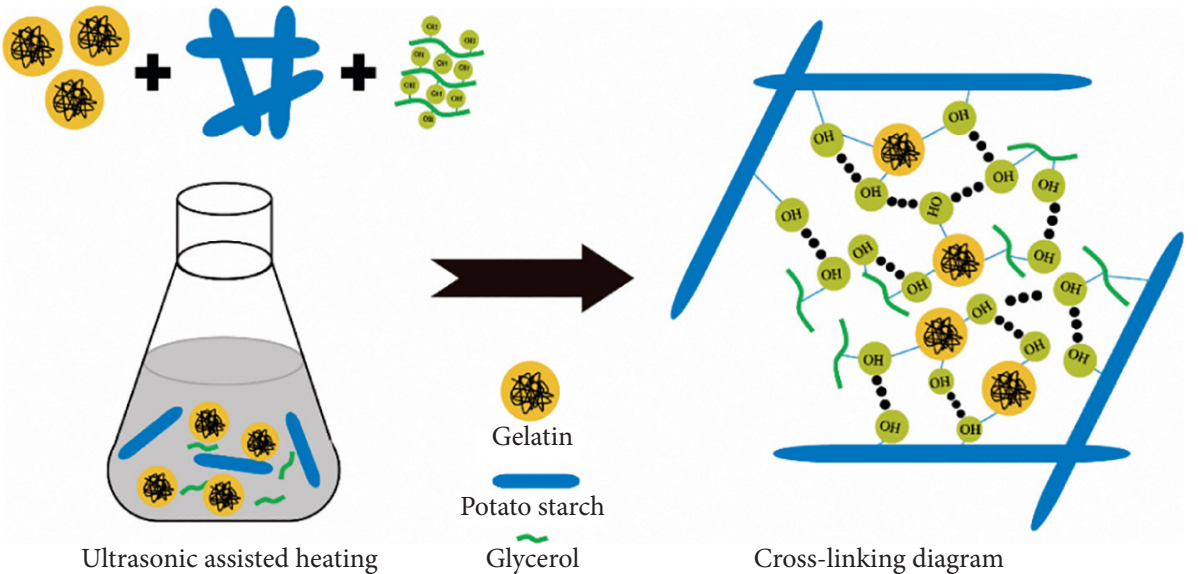

FIgURE 6: The schematic diagram of composite film.

compatibility between matrixes and were consistent with the SEM and rheology measurements.

\section{Conclusions}

A comprehensive performance film was successfully fabricated with biodegradable materials (starch, glycerol, and gelatin), and its formulation was optimized by using RSM. Responses, including mechanical, physical, and barrier properties, were subjected to a comprehensive multi-index evaluation. The RSM results verified the reliability of the model, and the optimized film exhibited excellent performance. In addition, the verification result indicated that the experimental values were highly consistent with the model-predicted values, and the optimal preparation conditions were $2.5 \%$ starch, $2 \%$ glycerol, and $1.5 \%$ gelatin. Rheological measurements proved that the film-forming solution exhibited non-Newtonian fluid behavior with low shear viscosity. Moreover, FTIR and SEM analysis demonstrated that the optimized films showed homogeneous with smooth microstructures, indicating good compatibility. In this work, the resulting biodegradable starch-based film with great comprehensive performance may be expected to become a green food packaging. 


\section{Data Availability}

The data used to support the study are included within the article. Raw data can be acquired from the corresponding author upon reasonable request (Causunjf@hebau.edu.cn).

\section{Conflicts of Interest}

The authors declare that there are no conflicts of interest regarding the publication of this paper.

\section{Acknowledgments}

This research was funded by the Program of the Hebei Youth Top-notch Talent Supporting Plan (0316027) and the Youth Top Talent Project of Hebei Provincial Department of Education (BJ2020060). Research of Key Technologies and Development of Product for Comprehensive Utilization of Potato (20327103D).

\section{References}

[1] N. Janani, E. N. Zare, F. Salimi, and P. Makvandi, "Antibacterial tragacanth gum-based nanocomposite films carrying ascorbic acid antioxidant for bioactive food packaging," Carbohydrate Polymers, vol. 247, Article ID 116678, 2020.

[2] Z. Wang, S. Hu, and H. Wang, "Scale-up preparation and characterization of collagen/sodium alginate blend films," Journal of Food Quality, vol. 2017, Article ID 4954259, 10 pages, 2017.

[3] A. Ju and K. B. Song, "Active biodegradable films based on water soluble polysaccharides from white jelly mushroom (Tremella fuciformis) containing roasted peanut skin extract," LWT-food Science and Technology, vol. 126, Article ID 109293, 2020.

[4] A. Malik, S. Parveen, T. Ahamad, S. M. Alshehri, P. K. Singh, and N. Nishat, "Coordination polymer: synthesis, spectral characterization and thermal behaviour of starch-urea based biodegradable polymer and its polymer metal complexes," Bioinorganic Chemistry and Applications, vol. 2010, Article ID 848130, 8 pages, 2010.

[5] Y. A. Alamerew and D. Brissaud, "Modelling reverse supply chain through system dynamics for realizing the transition towards the circular economy: a case study on electric vehicle batteries," Journal of Cleaner Production, vol. 254, Article ID 120025, 2020.

[6] M. Brouwer, C. Picuno, E. U. Thoden van Velzen, K. Kuchta, S. De Meester, and K. Ragaert, "The impact of collection portfolio expansion on key performance indicators of the Dutch recycling system for post-consumer plastic packaging waste, a comparison between 2014 and 2017," Waste Management, vol. 100, pp. 112-121, 2019.

[7] H. Hashemi Gahruie, R. Safdarianghomsheh, P. Zamanifar, S. Salehi, M. Niakousari, and S. M. H. Hosseini, "Characterization of novel edible films and coatings for food preservation based on gum cordia," Journal of Food Quality, vol. 2020, Article ID 8883916, 7 pages, 2020.

[8] S. Li, Y. Ma, T. Ji et al., "Cassava starch/carboxymethylcellulose edible films embedded with lactic acid bacteria to extend the shelf life of banana," Carbohydrate Polymers, vol. 248, Article ID 116805, 2020.

[9] X. Zhou, X. Ye, J. He, R. Wang, and Z. Jin, "Effects of electron beam irradiation on the properties of waxy maize starch and its films," International Journal of Biological Macromolecules, vol. 151, pp. 239-246, 2020.

[10] W. H. Teklehaimanot, S. S. Ray, and M. N. Emmambux, "Characterization of pre-gelatinized maize starch-zein blend films produced at alkaline $\mathrm{pH}$," Journal of Cereal Science, vol. 95, Article ID 103083, 2020.

[11] M. E. Hoque, T. J. Ye, L. C. Yong, and K. Mohd Dahlan, "Sago starch-mixed low-density polyethylene biodegradable polymer: synthesis and characterization," Journal of Materials, vol. 2013, Article ID 365380, 7 pages, 2013.

[12] R. Wang, P. Liu, B. Cui et al., "Effects of pullulanase debranching on the properties of potato starch-lauric acid complex and potato starch-based film," International Journal of Biological Macromolecules, vol. 156, pp. 1330-1336, 2019.

[13] P. Hernandez-Perez, P. C. Flores-Silva, G. Velazquez et al., "Rheological performance of film-forming solutions made from plasma-modified starches with different amylose/amylopectin content," Carbohydrate Polymers, vol. 225, Article ID 117349, 2020.

[14] Y. Zou, C. Yuan, B. Cui, P. Liu, Z. Wu, and H. Zhao, "Formation of high amylose corn starch/konjac glucomannan composite film with improved mechanical and barrier properties," Carbohydrate Polymers, vol. 251, Article ID 117039, 2021.

[15] P. Pająk, I. Przetaczek-Rożnowska, and L. Juszczak, "Development and physicochemical, thermal and mechanical properties of edible films based on pumpkin, lentil and quinoa starches," International Journal of Biological Macromolecules, vol. 138, pp. 441-449, 2019.

[16] Y. Qin, Y. Liu, H. Yong, J. Liu, X. Zhang, and J. Liu, "Preparation and characterization of active and intelligent packaging films based on cassava starch and anthocyanins from Lycium ruthenicum Murr," International Journal of Biological Macromolecules, vol. 134, pp. 80-90, 2019.

[17] R. Chollakup, S. Pongburoos, W. Boonsong et al., "Antioxidant and antibacterial activities of cassava starch and whey protein blend films containing rambutan peel extract and cinnamon oil for active packaging," LWT-food Science and Technology, vol. 130, Article ID 109573, 2020.

[18] Z. Lin, Y. Xia, G. Yang, J. Chen, and D. Ji, "Improved film formability of oxidized starch-based blends through controlled modification with cellulose nanocrystals," Industrial Crops and Products, vol. 140, Article ID 111665, 2019.

[19] S. Collazo-Bigliardi, R. Ortega-Toro, and A. Chiralt, "Using lignocellulosic fractions of coffee husk to improve properties of compatibilised starch-PLA blend films," Food Packaging and Shelf Life, vol. 22, Article ID 100423, 2019.

[20] H. Zhang, F. Xu, Y. Wu, H.-H. Hu, and X.-F. Dai, "Progress of potato staple food research and industry development in China," Journal of Integrative Agriculture, vol. 16, no. 12, pp. 2924-2932, 2017.

[21] Z. Xu, Z. Fu, Z. Zhai et al., "Comparative evaluation of carbon footprints between rice and potato food considering the characteristic of Chinese diet," Journal of Cleaner Production, vol. 257, Article ID 120463, 2020.

[22] Z. Zhao, T. Mu, and H. Sun, "Microbial characterization of five Chinese traditional sourdoughs by high-throughput sequencing and their impact on the quality of potato steamed bread," Food Chemistry, vol. 274, pp. 710-717, 2019.

[23] H. Li, F. Zhai, J. Li et al., "Physicochemical properties and structure of modified potato starch granules and their complex with tea polyphenols," International Journal of Biological Macromolecules, vol. 166, pp. 521-538, 2020. 
[24] G. Oliveira, I. Gonçalves, A. Barra, C. Nunes, P. Ferreira, and M. A. Coimbra, "Coffee silverskin and starch-rich potato washing slurries as raw materials for elastic, antioxidant, and UV-protective biobased films," Food Research International, vol. 138, Article ID 109733, 2020.

[25] R. Thakur, P. Pristijono, C. J. Scarlett, M. Bowyer, S. P. Singh, and Q. V. Vuong, "Starch-based films: major factors affecting their properties," International Journal of Biological Macromolecules, vol. 132, pp. 1079-1089, 2019.

[26] M. Radi, E. Firouzi, H. Akhavan, and S. Amiri, "Effect of gelatin-based edible coatings incorporated with aloe vera and black and green tea extracts on the shelf life of fresh-cut oranges," Journal of Food Quality, vol. 2017, Article ID 9764650, 10 pages, 2017.

[27] F. Matta Fakhouri, G. F. Nogueira, R. A. de Oliveira, and J. I. Velasco, "Bioactive edible films based on arrowroot starch incorporated with cranberry powder: microstructure, thermal properties, ascorbic acid content and sensory analysis," Polymers, vol. 11, 2019.

[28] Z. Nasreen, M. A. Khan, and A. I. Mustafa, "Improved biodegradable radiation cured polymeric film prepared from chitosan-gelatin blend," Journal of Applied Chemistry, vol. 2016, Article ID 5373670, 11 pages, 2016.

[29] N. S. Resende, G. A. S. Gonçalves, K. C. Reis, G. H. D. Tonoli, and E. V. B. V. Boas, "Chitosan/cellulose nanofibril nanocomposite and its effect on quality of coated strawberries," Journal of Food Quality, vol. 2018, Article ID 1727426, 13 pages, 2018.

[30] G. Sun, T. Liang, W. Tan, and L. Wang, "Rheological behaviors and physical properties of plasticized hydrogel films developed from $\kappa$-carrageenan incorporating hydroxypropyl methylcellulose," Food Hydrocolloids, vol. 85, pp. 61-68, 2018.

[31] Y. Zhu and J. Gao, "Effect of package film on the quality of postharvest Chinese toon tender shoots storage," Journal of Food Quality, vol. 2017, Article ID 5605202, 6 pages, 2017.

[32] Q. Ma, L. Du, and L. Wang, "Tara gum/polyvinyl alcoholbased colorimetric $\mathrm{NH} 3$ indicator films incorporating curcumin for intelligent packaging," Sensors and Actuators B: Chemical, vol. 244, pp. 759-766, 2017.

[33] K. Zhang, T.-S. Huang, H. Yan, X. Hu, and T. Ren, "Novel pHsensitive films based on starch/polyvinyl alcohol and food anthocyanins as a visual indicator of shrimp deterioration," International Journal of Biological Macromolecules, vol. 145, pp. 768-776, 2020.

[34] Q. Ma, D. Hu, and L. Wang, "Preparation and physical properties of tara gum film reinforced with cellulose nanocrystals," International Journal of Biological Macromolecules, vol. 86, pp. 606-612, 2016.

[35] J. Peng, V. Calabrese, S. J. Veen et al., "Rheology and microstructure of dispersions of protein fibrils and cellulose microfibrils," Food Hydrocolloids, vol. 82, pp. 196-208, 2018.

[36] W. Li, J. Wu, Z. Zhang, L. Wu, and Y. Lu, "Investigation on the synthesis process of bromoisobutyryl esterified starch and its sizing properties: viscosity stability, adhesion and film properties," Polymers, vol. 11, Article ID 1936, 2019.

[37] J. Glusac, I. Davidesko-Vardi, S. Isaschar-Ovdat, B. Kukavica, and A. Fishman, "Gel-like emulsions stabilized by tyrosinasecrosslinked potato and zein proteins," Food Hydrocolloids, vol. 82, pp. 53-63, 2018.

[38] A. Haddarah, A. Bassal, A. Ismail et al., "The structural characteristics and rheological properties of Lebanese locust bean gum," Journal of Food Engineering, vol. 120, pp. 204-214, 2014.
[39] R. Hussain, H. Vatankhah, A. Singh, and H. S. Ramaswamy, "Effect of high-pressure treatment on the structural and rheological properties of resistant corn starch/locust bean gum mixtures," Carbohydrate Polymers, vol. 150, pp. 299-307, 2016.

[40] W. Theerawitayaart, T. Prodpran, S. Benjakul, K. Nilsuwan, and K. de la Caba, "Storage stability of fish gelatin films by molecular modification or direct incorporation of oxidized linoleic acid: comparative studies," Food Hydrocolloids, vol. 113, Article ID 106481, 2020.

[41] X. Zhai, J. Shi, X. Zou et al., "Novel colorimetric films based on starch/polyvinyl alcohol incorporated with roselle anthocyanins for fish freshness monitoring," Food Hydrocolloids, vol. 69, pp. 308-317, 2017.

[42] Q. Ma, S. Liang, S. Xu, J. Li, and L. Wang, "Characterization of antioxidant properties of soy bean protein-based films with Cortex Phellodendri extract in extending the shelf life of lipid," Food Packaging and Shelf Life, vol. 22, Article ID 100413, 2019.

[43] Q. Ma, Y. Ren, and L. Wang, "Investigation of antioxidant activity and release kinetics of curcumin from tara gum/ polyvinyl alcohol active film," Food Hydrocolloids, vol. 70, pp. 286-292, 2017.

[44] G. Jiang, X. Hou, X. Zeng et al., "Preparation and characterization of indicator films from carboxymethyl-cellulose/ starch and purple sweet potato (Ipomoea batatas (L.) lam) anthocyanins for monitoring fish freshness," International Journal of Biological Macromolecules, vol. 143, pp. 359-372, 2020. 